\title{
The effects of nesting stage, sex, and type of predator on parental defense by killdeer (Charadrius vociferous): testing models of avian parental defense
}

\author{
Dianne H. Brunton * \\ School of Natural Resources, University of Michigan, Ann Arbor, Michigan, MI 48109-1115, USA
}

Received July 19, 1988 / Accepted September 16, 1989

Summary. Two models predicting the temporal patterns of parental investment in offspring defense over the nesting cycle were tested. The first is based on offspring age, the other on the vulnerability of offspring to predation. Both models make very similar predictions for altricial species after eggs have hatched, i.e., increases in intensity of parental defense until fledging. For precocial species, however, the post-hatching predictions of each model are different: the offspring age model predicts a continued increase in defense intensity, while the vulnerability model predicts a decline. I examined the temporal patterns of parental defense of a precocial shorebird, the killdeer (Charadrius vociferus), and determined which model was supported. Killdeer responses to human and natural predators were observed. Killdeer were less willing to leave the nest, responded most intensely, and displayed closest to a potential predator around hatching. Defense intensity increased from early to late incubation as predicted by the offspring age model. However, after hatching killdeer parental defense declined for both males and females, thus supporting the vulnerability model for this stage. Males and females responded significantly differently to all types of predators. Males took greater risks, remained on the nest longer, defended offspring more intensely, and displayed closer to the predator than females at the approach of a potential predator. Responses to natural predators depended on the type of predator and the approach made by the predator; a greater range of defense behavior was used for predators approaching on the ground compared to aerial predators. In general, killdeer responses to humans were more intense and less variable than their re-

\footnotetext{
* Present address: Department of Biology, Yale University, OML, P.O. Box 6666, New Haven, CT 06511-7444, USA
}

sponses to natural predators. This was most likely because the human intruder approached nests and chicks more directly and closer than natural predators.

\section{Introduction}

Parental defense and its associated risks are an important component of parental investment (Trivers 1972). Predation is a powerful selective pressure and in species with parental care, parents often enhance the survival of their offspring by actively defending them from predators (Gottfried 1979; Greig-Smith 1980; Gochfeld 1984). Defense behavior is assumed to be performed at some risk to the defending bird (Simmons 1955; Armstrong 1956; Kruuk 1964; Barash 1975; Andersson et al. 1980; Greig-Smith 1980; Walters 1982; Weatherhead 1982; Brunton 1986). Although distraction displays, in particular injury-feigning, appear to place the performing bird at a greater risk of predation, the actual risks are difficult to assess and may be small. Few observations of mortality of displaying adults have been made (Jourdain 1936; Myers 1978; Brunton 1986). The alertness of the displaying bird is considered evidence of the small probability of mortality (Gochfeld 1984), i.e., an alert bird is unlikely to be captured by a potential predator. At the very least, defending parents are expending time and energy that cannot be expended on somatic activities. Thus, selection should result in a level of defense that is a compromise between the benefit to the current brood and the survival of the parent and future broods (Trivers 1972).

The hypotheses developed within the cost/benefit framework of parental investment have been 


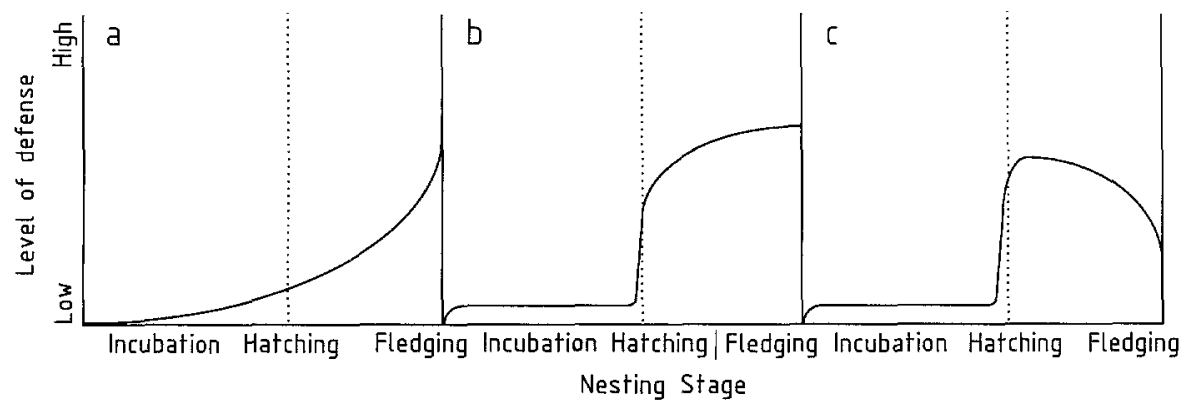

Fig. 1. Graphical representation of models of parental defense. Model 1 predicts that levels of parental defense correlate with offspring age (a). Model 2 predicts levels of parental defense correlate with offspring vulnerability and, thus, predicts different relationships for altricial species (b), where vulnerability continues to increase after hatching until fledging, and for precocial species (c), where vulnerability peaks at hatching

recently reviewed by Montgomerie and Weatherhead (1988). Two of these hypotheses make predictions concerning the temporal changes in the intensity of defense behavior over the nesting cycle. The first hypothesis is based on offspring age (Barash 1975; Andersson et al. 1980). This hypothesis predicts an increase in nest defense through the breeding season as the difference between the reproductive value of offspring and parent decreases (Fig. $1 \mathrm{a}$; Andersson et al. 1980; Montgomerie and Weatherhead 1988). Offspring value increases exponentially as offspring overcome initial high juvenile mortality and near independence (Curio et al. 1984). The second hypothesis is based on the vulnerability of offspring to predation (Skutch 1949; Harvey and Greenwood 1978). This hypothesis predicts that the level of nest defense correlates with the vulnerability of offspring to predation (Fig. $1 \mathrm{~b}, \mathrm{c}$ ). The more vulnerable offspring are, due to their stage of development or physical location, the greater the intensity of parental defense.

Studies of parental defense have concentrated on altricial species and have revealed increases in the intensity of nest defense by parents as offspring increase in age (Erpino 1968; Barash 1975; Curio 1975; Weatherhead 1979; Greig-Smith 1980; Biermann and Robertson 1981; Merritt 1984; Shields 1984). Although the offspring age hypothesis and the vulnerability hypothesis make different predictions for altricial species during the egg stage, after hatching both hypotheses generate the prediction that defense should increase and peak just prior to fledging (Fig. 1a, b). Barash (1975) predicted a major difference in the temporal pattern of parental defense between altricial and precocial spe- cies based on vulnerability to predation. Chick vulnerability tends to increase until fledging (or when chicks can move out of the nest) for altricial species because of increasing conspicuousness of the nest (Skutch 1949; Barash 1975; Harvey and Greenwood 1978; East 1981; Gochfeld 1984; Andersson et al. 1980). In contrast, chick vulnerability peaks at hatching and decreases thereafter for precocial species because of increasing chick mobility (Armstrong 1956; Barash 1975; Fig. 1c). Furthermore, parental defense for precocial species is independent of brood size after hatching, as defense is unshared parental investment and predators usually only take a single offspring (Lazarus and Inglis 1986). Hence, if offspring age has the greater impact on intensity of defense for precocial species, then defense should increase throughout the nesting cycle and peak just prior to fledging (Fig. 1a), but if chick vulnerability to predation is more important, then defense should be constant during the egg stage, peak at hatching, and thereafter decrease (Fig. 1 c).

Variation in levels of defense may also differ with the sex of the parent (Burger 1981; Ashkenazie and Safriel 1979; Greig-Smith 1980; Montevecchi and Porter 1980; Pierotti 1981; Mundahl 1982; Regelmann and Curio 1983). These differences are usually consistent with those predicted by sexual selection and parental investment theory (but see Howe 1982). If there are differences between the sexes in levels of defense, then these must be controlled for in any study examining temporal changes in defense.

Finally, parental defense behavior will be influenced by the "risk" posed by a potential predator (Kruuk 1964; Lemmetyinen 1971; Curio 1975; Greig-Smith 1980; Patterson et al. 1980; Buitron 1983; Gochfeld 1984). The species of predator, its approach, and the distance the predator is from the offspring are all important factors. Individuals should respond differently to predators that are capable of taking both adults and offspring compared to predators that can only take offspring.

In this study I examine how the intensity of 
parental defense by killdeer (Charadrius vociferus) varies with nesting stage, sex of the defending parent, and the type of predator. I test which of two models is supported by comparing parental defense behavior of a precocial species over all nesting stages. I also examine the effects of the sex of the defending parent, type of predator, and predator approach, on defense behavior.

Killdeer are common North American shorebirds. They are ground nesting birds that suffer heavy nest and hatchling mortality (Nol 1980; Nol and Lambert 1984; Brunton 1987). Studies of killdeer time-budgets (Lenington 1980; Brunton 1988a) and energy expenditures (Brunton 1988b) support the general hypothesis that males and females maximize fitness in different ways. The parental roles of the sexes, however, were not those generally predicted for a monogamous species; males allocated more time and energy than females to parental activities (Phillips 1972; Mundahl 1982; Brunton 1988a, b). Chicks are precocial, leave the nest within $24 \mathrm{~h}$ of hatching, and are not fed by their parents. Killdeer parental care includes incubating and guarding eggs, brooding, and leading and defending chicks (Phillips 1972; Lenington 1980; Mundahl 1982).

\section{Methods}

\section{Study areas}

During 1984 and 1985 I studied 87 nesting attempts by 41 pairs of killdeer (see Brunton 1987, 1988 a for descriptions of the study sites). Nests were located by observing the behavior of adults. All defense behavior observations were made on individuals identifiable by dyed plumage, color bands or unique plumage characteristics. Observations were made from two $5 \mathrm{~m}$ towers and from a car. Nests were checked every 2-5 days until nests failed or chicks hatched. After hatching, pairs with broods were monitored at least weekly until chicks fledged.

\section{Definitions of parental defense}

Parental defense behavior of killdeer was studied by observing their responses to controlled approaches by human intruders and approaches by natural predators. Among Charadriidae, distraction displays are a common defense behavior, and apparently are quite effective at leading potential predators away from the nest and chicks (Larson 1960; Bengtson 1970; Hobbs 1972). Gochfeld (1984) gives the most thorough review of shorebird defense behavior, and I use his terminology. Killdeer respond to potential predators in a variety of ways, including both cryptic behavior and distraction displays (Phillips 1972; Mundahl 1982). These responses were ranked in terms of intensity: quiet departure (0), standing alert or calling (1), crouched or upright run (2), false-brooding (3), low, medium and high intensity injury-feigning $(4,5,6)$, and threat display (7). As injury-feigning involved a continuum of intensities, the division of this behavior into low, medium, and high was determined based on the following descriptions: low intensity partial extension of both wings $<30^{\circ}$ from the body, legs flexed, and partial or no fanning of the tail; medium intensity asymmetrical extension of the wings from the body, with one wing extended $>30^{\circ}$ from the body, legs flexed to fully crouched, and partial to full fanning of the tail; high intensity almost symmetrical extension of the wings with both wings $>30^{\circ}$ from the body, legs fully crouched with breast pressed to the substrate, and tail fully fanned. Threat displays (see also "ungulate display" Gochfeld 1984) involve the killdeer running towards the predator while holding the wings symmetrically out from the body. All defense behavior, with the exception of quiet departure and standing alert, were considered "distraction displays".

To assess differences between nesting stages, I divided the nesting cycle into six stages: pre-laying ( $x=10$ days), pair formation and arrival on the breeding grounds; egg-laying ( $\mathrm{x}=$ 6 days), first egg laying to clutch completion; incubation ( $\mathrm{x}=$ 24 days), divided into early incubation, 1 to 12 days after clutch completion, and late incubation, 12 days after clutch completion until hatching; and chick dependence (approximately 34 days), divided into brooding, 1 to 15 days, and post-brooding, 15 days until fledging.

Male and female defense behavior during early nesting attempts, initiated prior to 10 June, and late nesting attempts, initiated after $10 \mathrm{June}$, were also compared.

\section{Responses to human intruders}

Parental defense by killdeer was measured by recording three aspects of defense behavior to a human intruder at the nest or chicks: (1) "response distance", the distance between the intruder and nest, or chicks, at which I firsti perceived a change in behavior of the incubating, or tending parent, (initial responses to an approaching intruder usually differed from responses given to an intruder at the nest), (2) "response intensity", as ranked above; for each sample the most risky behavior was recorded, and (3) minimum "distraction display distance", the minimum distance between an intruder and a displaying bird. Distraction display distances were ranked: greater than $33 \mathrm{~m} \mathrm{(1),} 16$ to $32 \mathrm{~m} \mathrm{(2),} 8$ to $15 \mathrm{~m} \mathrm{(3),} 4$ to $7 \mathrm{~m} \mathrm{(4),} 2$ to $3 \mathrm{~m} \mathrm{(5)}$, and less than $2 \mathrm{~m}(6)$. I made a total of 626 approaches to 87 nests. There was no correlation between the frequency of human visits to nests and the probability of predation (Brunton 1987). The sexes of all birds were known from observations of copulation behavior. To avoid habituation to the human intruder, nest or chick approaches were made no more than once every two days (mean interval duration over entire breeding attempt was 6 days). To reduce the influence of environmental variables, nest approaches were made between 0700 and 1000 hours or 1700 and 2000 hours, but not when it was raining. After observing the pair in order to determine the identity of the incubating or tending parent and the location of its mate, I approached the nest or chicks at a slow walk, beginning approximately $200 \mathrm{~m}$ from the nest or closest chick. Observations were made using a portable tape recorder. Upon reaching the nest or vicinity of the chicks, I remained standing for $3 \mathrm{~min}$ while continuously recording the behavior and distance of the focal animal and, when possible, the behavior and location of the other parent. Samples sizes of males and females were as equal as possible in order to avoid biases due to the different amounts of time the sexes spend incubating, brooding, and tending young (Brunton 1988a).

\section{Risk-taking}

Regardless of the actual cost of distraction displays, it is likely that the closer an adult is to a potential predator, and the 
more intense its display, the greater the risk relative to other behavior. To compare risk taking by the sexes and over different nesting stages, I used a risk index derived from Windt and Curio (1986); risk $=\sum \mathrm{R}\left(t_{r} / d_{r}\right)$, where $R$ is the rank value of each defence behavior $r, t_{r}$ is time spent in behavior $r$, and $d_{r}$ is the mean distance from the predator during $t_{r}$. A risk value was calculated for each 3-min sample period. Low values for $R$ mean that only a low risk is taken. The major assumptions of the risk index were that risk of injury or death increases (1) the closer the defending parent is to the potential predator and (2) with increasing intensity of response behavior (Barash 1975; Andersson et al. 1980).

\section{Responses to natural predators}

Approximately 1000 approaches by natural predators were observed during more than $2000 \mathrm{~h}$ of behavioral observations made throughout all nesting stages. A potential predator was considered to approach a nest when it got to within $33 \mathrm{~m}$ of the nest or chicks (clear observations past this distance were difficult because of ground cover or topography). Response intensity and the minimum display distance of both parents were recorded when possible. Response distance was difficult to assess as predators were often spotted by killdeer pairs before I noticed their approach. Approaches by avian predators could be aerial, ground, or a combination. The type of predator, direction of approach, duration, or time of day could not be controlled; therefore, the sample sizes were unequal and killdeer responses likely to be quite variable.

\section{Statistical procedures}

Data were analyzed on an Apple Macintosh using the software packages Multiplan, Excel, Statfast, and Systat. Differences in frequency distributions were tested using the Chi-squared test of independence ( $\chi^{2}$ tests). The non-parametric Wilcoxon Rank Sum test (WRS test) was used on all categorical data. A significance level of $\alpha<0.05$ (2-tailed) was used for all statistical tests.

\section{Results}

\section{Sex, nesting stage, and ground predators (humans)}

Response distance varied from 4-7 $\mathrm{m}$ to $>33 \mathrm{~m}$ for all nesting stages, and the only significant differences between males and females were observed during incubation and post-brooding (Fig. 2). When significant differences existed between the sexes, it was always female response distance that was greater; females moved from the vicinity of the nest or chicks sooner than males. Females showed no variation in the most frequent response distance during all stages; it was always $>33 \mathrm{~m}$, whereas males showed considerable variation (Fig. 2). The most frequent male response distance decreased from $>33 \mathrm{~m}$ during egg-laying to $16-32 \mathrm{~m}$ during the remaining stages.

Killdeer responses to human intruders during early and late nesting attempts were not significantly different ( $\chi^{2}$ tests, $P>0.23$ ). For this reason,

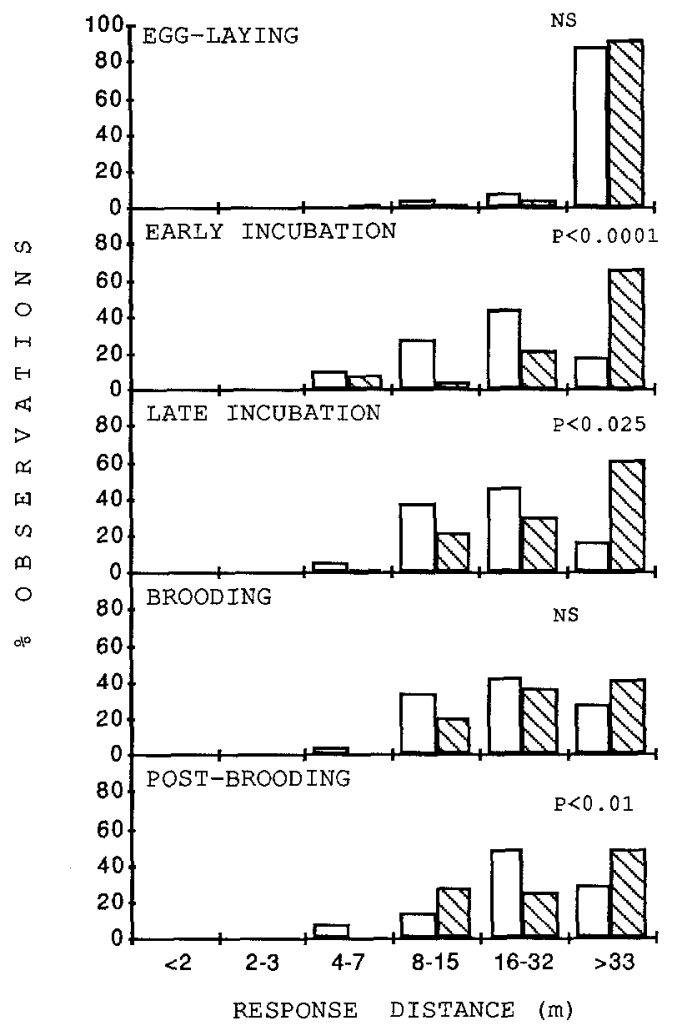

Fig. 2. Histograms comparing male (open bars) and female (striped bars) response distance to a human intruder at the nest or chicks. Response distance is the distance between the incubating or tending bird and the intruder at which a change in behavior is first observed. Chi-squared tests were used to determine significant differences. Samples sizes (males, females) for each nesting stage were: egg-laying $(31,27)$, early incubation $(58,55)$, late incubation $(78,66)$, brooding $(97,71)$, and postbrooding $(89,54)$

observations of approaches to early and late nests were combined for all subsequent comparisons.

Although responses to human intruders varied from quiet departure to threat (Fig. 3), males and females responded significantly differently during all nesting stages (Fig. $3, \chi^{2}$ tests, $P<0.0005$ ), and the most frequent response was more intense for males than females. Males and females differed in their responses according to nesting stage, with the most intense responses occurring during late incubation (Fig. 3).

Responses were moderate during egg-laying; females departed the nest site quietly and did not attempt to distract a human at the nest site, whereas males responded by standing nearby and calling. The intensity of response for both sexes increased once incubation started. The most frequent male response during early incubation was low intensity injury-feigning compared to the most frequent female response of false brooding. As incubation 


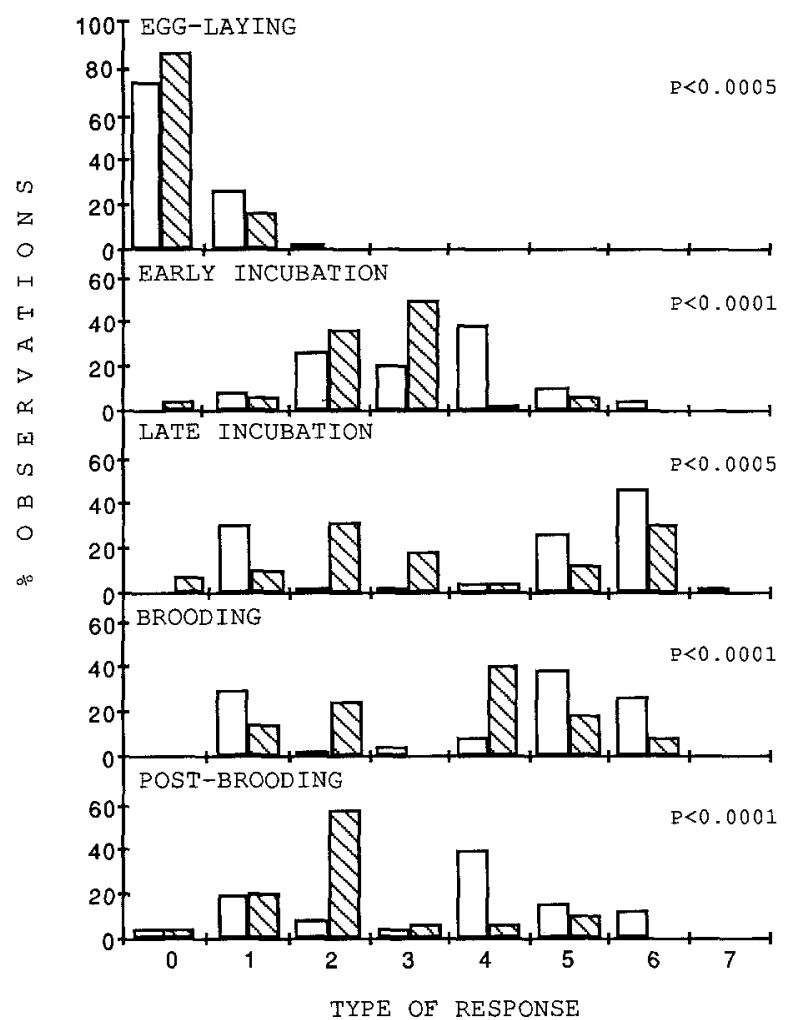

Fig. 3. Histograms comparing the frequency of various killdeer responses to human intruders. Chi-squared tests were used to determine significant differences between male (open bars) and female (striped bars). The intensities of defense behaviors are: $0=$ quiet departure, $1=$ standing alert or calling, $2=$ crouched or upright run, $3=$ false brooding, $4=$ low intensity injury-feigning, $5=$ medium intensity injury-feigning, $6=$ high intensity injury-feigning, $7=$ threat display. Sample sizes are shown in Fig. 2

progressed, more intense responses were observed. Responses remained intense during brooding, with the most frequent male response being medium intensity injury-feigning and the most frequent female response being low intensity injury-feigning. During post-brooding, the intensity of response decreased for both sexes.

Specifically comparing injury-feigning responses (low, medium, and high) for all stages, I found that males were more likely to injury-feign than females; $18.2 \%$ compared to $55.8 \%$ of human approaches $\left(n=626, \chi^{2}\right.$ test, $\left.P<0.0001\right)$. Males were also more likely to injury-feign when they were incubating or tending young; $62.8 \%$ (182/290) compared to $28.3 \%(75 / 265)$ for females $\left(\chi^{2}\right.$ test, $\left.P<0.001\right)$. Furthermore, non-incubating or non-tending males were more likely to injuryfeign $(52.5 \%, 167 / 318)$ than non-incubating or non-tending females $\left(25.3 \%, 39 / 154, \chi^{2}\right.$ test, $P<$ 0.001 ).

The minimum distraction display distances var-

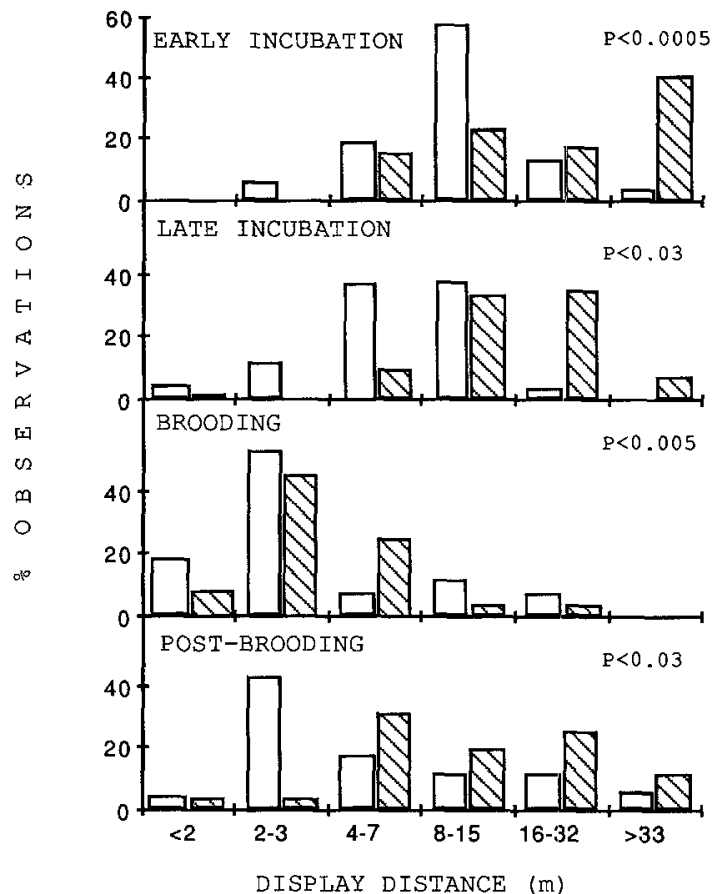

Fig. 4. Histograms comparing the distraction display distance of males (open bars) and females (striped bars) to human intruders at the nest or chicks over each nesting stage. Distributions were compared using Chi-squared tests. Samples sizes (males, females) for each nesting stage were: early incubation $(57,53)$, late incubation $(78,66)$, brooding $(97,67)$, and postbrooding $(84,38)$

ied with the sex of the displaying bird and the nesting stage (Fig. 4). Males displayed significantly closer than females during every nesting stage (Fig. 4). The most frequent minimum distraction display distances were lower for males than females during all stages except brooding, when the most frequent distance was $2-3 \mathrm{~m}$. For both sexes, display distances decreased from early to late incubation, were lowest during brooding, and increased slightly during post-brooding (Fig. 4). During 287/452 approaches where both parents were present, warning calls were given by non-incubating or non-tending males and females prior to a response from the incubating or tending parent.

Risk-taking for both sexes increased from prelaying to hatching, peaked at hatching, and decreased after hatching (Fig. 5). Risk-taking values were significantly greater for males than females during early incubation (WRS test, $P<0.03$ ), late incubation (WRS test, $P<0.009$ ), and post-brooding (WRS test, $P<0.04$ ). Male and female risk- 
(A) MALES

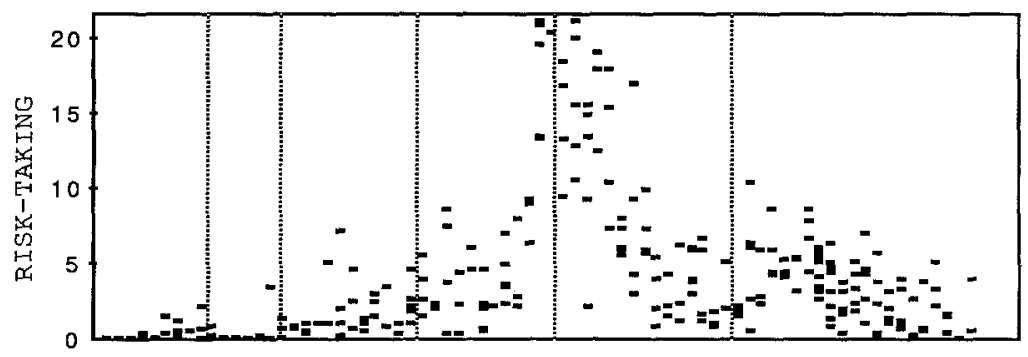

(B) FEMALES

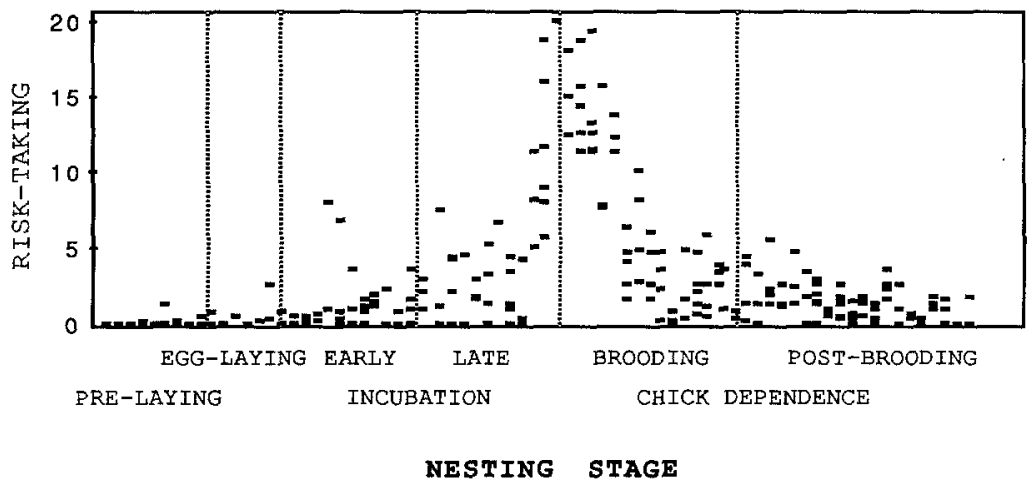

Fig. 5. Risk-taking by (a) male and (b) female killdeer during a nesting attempt (for explanation of risk index see "Methods"). Sample sizes (males, females) for each of nesting stage were: pre-laying $(22,16)$, egg-laying $(13,16)$, early incubation $(41$, $40)$, late incubation $(44,42)$, brooding $(68,64)$, post-brooding $(89,76)$

taking was not significantly different during egglaying (WRS test, $P=0.65$ ) and brooding (WRS test, $P=0.37)$.

\section{Natural predators}

Although 53.4\% of eggs were lost, I observed the depredation of only five nests: two by herring gulls (Larus argentatus), two by common crows (Corvus corvus), and one by a raccoon (Procyon lotor). Crows and skunks (Mephitis mephitis) were the most common avian and mammalian predators at Houghton Lake (Table 1). During 1984 and 1985 I observed 1017 approaches by potential predators. Responses to natural predators by killdeer were observed throughout all nesting stages. One adult mortality was observed; the injury-feigning parent was captured by a fox a short distance from the nest (Brunton 1986).

In general, the level of response to predators was greater during incubation than during chick dependence (Fig. 6). The one exception was male responses to aerial predators, where responses were more intense during chick dependence. Males and females responded in different ways to ground and aerial predators (Fig. 6). The most frequent response of males was more intense than that of females to ground predators during incubation (medium intensity injury-feigning compared to quiet departure, $\chi^{2}$ test, $\left.P<0.01\right)$ and chick dependence (standing calling compared to standing quietly, $\chi^{2}$ test, $P<0.0001)$ and to aerial predators during chick dependence (standing calling compared to standing quietly, $\chi^{2}$ test, $P<0.0001$ ). During incubation, males and females did not respond significantly differently $\left(\chi^{2}\right.$ test, $\left.P=0.35\right)$; quiet departure was the most frequent response.

Killdeer responded differently to ground predators compared to aerial predators. Killdeer behaved with a greater range of responses to ground predators compared to aerial predators, using injury-feigning behavior more often towards ground predators (Fig. 6). Neither sex responded to an aerial predator by false brooding. Male responses to ground predators varied from sit-tight to threat, while responses to aerial predators varied from sit- 
Table 1. The observed number of approaches $(<33 \mathrm{~m})$ to killdeer nests or chicks by avian and mammalian potential predators during incubation (I) and chick dependence (CD), and the mode of each approach

\begin{tabular}{|c|c|c|c|c|}
\hline \multirow[t]{3}{*}{ Predator } & \multicolumn{4}{|c|}{ Mode of approach } \\
\hline & \multicolumn{2}{|c|}{ Ground } & \multicolumn{2}{|c|}{ Aerial } \\
\hline & I & $\mathrm{CD}$ & I & $\mathrm{CD}$ \\
\hline \multicolumn{5}{|l|}{ Avian } \\
\hline $\begin{array}{l}\text { Northern harrier } \\
\text { Circus cyaneus }\end{array}$ & - & - & 17 & 13 \\
\hline $\begin{array}{l}\text { Red-tailed hawk } \\
\text { Buteo jamaicensis }\end{array}$ & - & - & 8 & 2 \\
\hline $\begin{array}{l}\text { American kestrel } \\
\text { Falco sparverius }\end{array}$ & - & - & 3 & - \\
\hline $\begin{array}{l}\text { Herring gull } \\
\text { Larus argentatus }\end{array}$ & 84 & 34 & 95 & 58 \\
\hline $\begin{array}{l}\text { Common crow } \\
\text { Corvus corvus }\end{array}$ & 128 & 83 & 70 & 16 \\
\hline $\begin{array}{l}\text { Common grackle } \\
\text { Quiscalus quiscalus }\end{array}$ & 6 & - & - & - \\
\hline Total & 218 & 117 & 199 & 89 \\
\hline \multicolumn{5}{|l|}{ Mammalian } \\
\hline $\begin{array}{l}\text { Cat } \\
\text { Felis domesticus }\end{array}$ & 29 & 18 & & \\
\hline $\begin{array}{l}\text { Raccoon } \\
\text { Procyon lotor }\end{array}$ & 86 & 40 & & \\
\hline $\begin{array}{l}\text { Woodchuck } \\
\text { Marmota monax }\end{array}$ & 39 & 22 & & \\
\hline $\begin{array}{l}\text { Striped skunk } \\
\text { Mephitis mephitis }\end{array}$ & 92 & 18 & & \\
\hline $\begin{array}{l}\text { Red fox } \\
\text { Vulpes fulva }\end{array}$ & 3 & 2 & & \\
\hline $\begin{array}{l}\text { Muskrat } \\
\text { Ondatra zibethica }\end{array}$ & 6 & 1 & & \\
\hline Total & 255 & 103 & & \\
\hline
\end{tabular}

tight to low intensity injury-feigning. Female responses to ground predators varied from quiet departure to high intensity injury-feigning, while responses to aerial predators included only sit-tight and quiet departure.

I observed 177 distraction displays by males and 115 by females directed towards ground predators. Distraction display distances decreased from early to late incubation, were lowest during brooding, and increased during post-brooding. Male and female distraction display distances were significantly different during all nesting stages with males displaying closer to potential predators $\left(\chi^{2}\right.$ tests, $P<0.001$ ).

Predator responses to killdeer displays varied considerably. Killdeer displaying at low intensities were basically ignored by potential predators, although it was difficult to tell if predators were ac- (a) INCUBATION

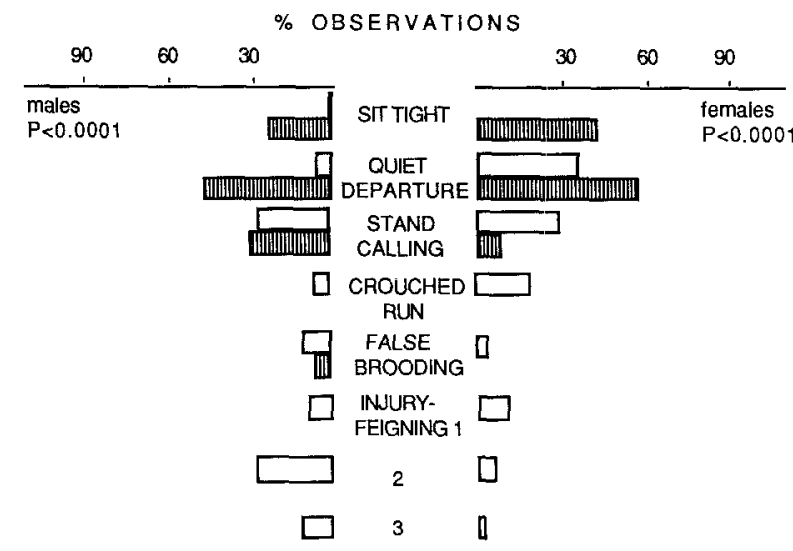

(b) CHICK DEPENDENCE

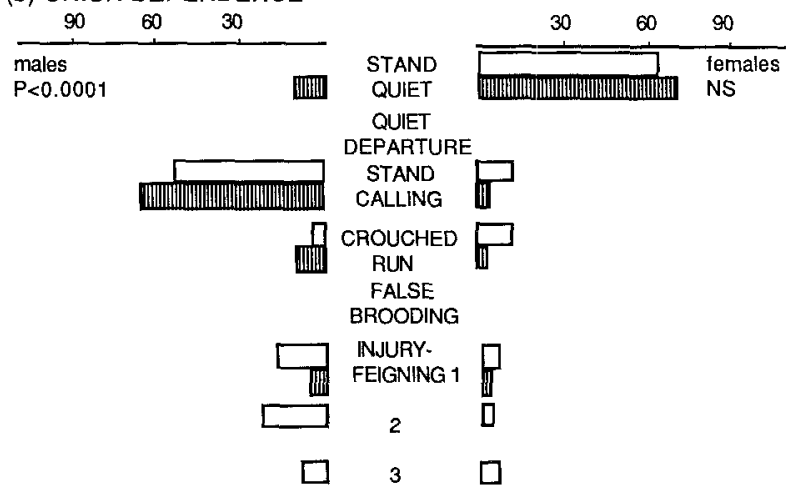

Fig. 6. Comparison between ground (open bars) and acrial (striped bars) predators and the type of response exhibited by males and females during (a) incubation and (b) chick dependence. Responses to ground and aerial predators were compared using Chi-squared tests. Male sample sizes (ground, aerial) were: incubation $(132,112)$ and chick dependence $(58,65)$. Female sample sizes (ground, aerial) were: incubation (123, $87)$ and chick dependence $(45,29)$

tively searching for nests. Mammalian predators essentially ignored killdeer false-brooding displays $(18 / 22)$, while avian predators on the ground tended to follow false-brooding killdeer $(23 / 31)$. All injury-feigning had a significant effect on mammalian predator behavior; predators followed injury-feigning killdeer in 76/146 observations. However, avian predators on the ground ignored injury-feigning killdeer 121/132 observations.

\section{Mode of predator approach: ground versus aerial}

Gulls and crows were the most common avian predators and are of approximately equal size. I observed 329 ground approaches and 239 aerial approaches by gulls and crows. There was a significant difference in the responses of killdeer to 
(a) INCUBATION

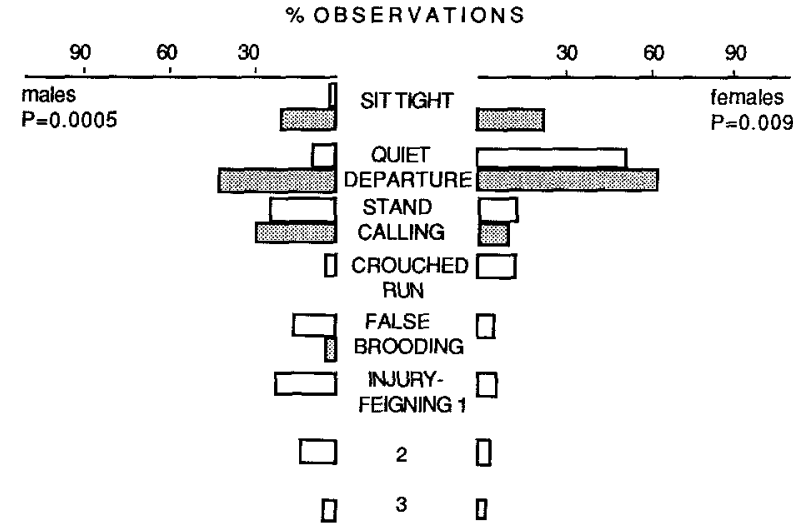

(b) CHICK DEPENDENCE

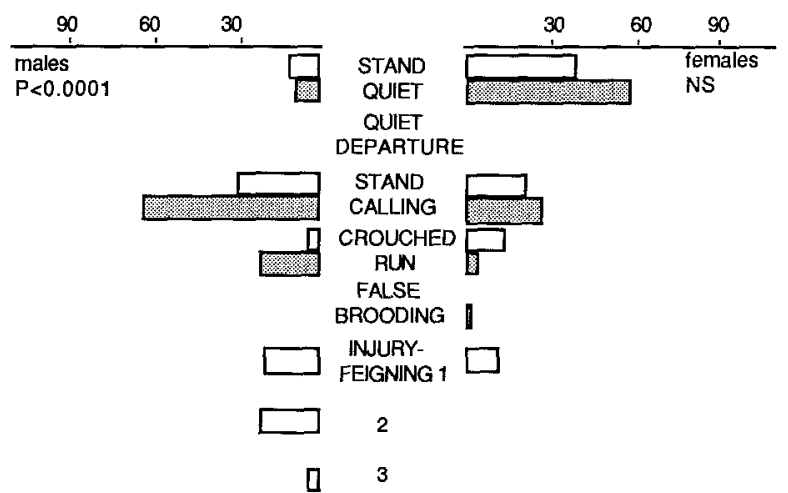

Fig. 7. Comparison between ground (open bars) and aerial (dotted bars) approaches by gulls and crows, and the type of response exhibited by males and females during (a) incubation and (b) chick dependence. Responses to ground versus aerial approaches were compared using Chi-squared tests. Male sample sizes (ground, aerial) were: incubation $(117,95)$ and chick dependence $(76,45)$. Female sample sizes (ground, aerial) were: incubation $(101,70)$ and chick dependence $(41,24)$

ground versus aerial approaches by avian predators (Fig. 7). Responses to ground approaches by gulls and crows were not significantly different from those given to mammalian predators (incubation: males $\chi^{2}=0.94$, females $\chi^{2}=1.76, P>0.05$; chick dependence: males $\chi^{2}=2.67$, females $\chi^{2}=$ $3.92, P>0.05$ ). As with responses to mammalian approaches, females responded less intensely than males, and responses to ground approaches by crows and gulls varied more.

\section{Discussion}

Evidence is presented that suggests there are consistent differences between the sexes - with nesting stage and with the species of predator and its mode of approach. The various measures of parental defense examined in this study, i.e., level of response, distraction display distance, and response distance, show that killdeer parental defense correlates with the ability of offspring to gain from defense. The most intense responses, medium and high intensity injury-feigning, were given by both males and females just after hatching. Distances between displaying birds and potential predators were shortest for both sexes around hatching and decreased after hatching as the chicks became more independent. Similar results have been seen in other precocial species (Simmons 1955; Gramza 1967). However, the overall pattern of risk-taking by killdeer supports both defense models at different stages; during early nesting stages increasing levels of defense are consistent with increasing offspring age (Fig. 1b), while later stages show decreasing levels of defense consistent with decreasing chick vulnerability (Fig. 1c).

Variation in the form, frequency, and level of defense between shorebird species has been observed; for example, species such as greater golden plovers Pluvialis apricaria (Ratcliffe 1977), lapwings, Vanellus spp, (Walters 1982), and Dunlins, Calidris alpina (Bent 1929) depart the nest early, whereas Australian Dotterels, Peltohyas australis (Maclean 1973), snipes, Gallinago spp, and woodcock, Scolopax spp, (Bent 1929) remain on the nest until the predator is very close. This study has shown that considerable variation also exists within a species.

\section{Sexual differences in parental defense}

Male and female killdeer performed all defense behaviors with the exception of the threat display. Thus, the observed frequencies of the various behaviors may represent differences in male and female strategies of defense behavior. Throughout all reproductive stages, female killdeer responses to human intruders were less intense than male responses. Females used cryptic behavior such as false brooding and quiet departure more often than males.

Killdeer response distance differed for males and females. Females tended to respond early to human intruders regardless of the reproductive stage. Earlier female response may be an indication of female reluctance to place herself at risk by remaining on the nest. Alternatively, this difference may have been due to the tendency for non-incubating males to give alarm calls more often than non-incubating females $(315 / 452$ compared to 
102/452). If males warn incubating or tending females more often, then females may be able to depart from the nest sooner. The contribution of the second parent needs further investigation.

Due to the difficulty of sexing shorebirds in the field, and of following birds after chicks have hatched, quantitative studies examining sexual differences in parental defense behavior are rare (Brown 1962; Gochfeld 1984). Males perform more defense than females in the majority of cases where differences occur (Gochfeld 1984). The apparent greater role of males in parental activities may be related to high nest losses among ground nesters and thus to the importance of females being in good condition to produce replacement clutches (Mundahl 1982; Walters 1982; Brunton 1988b). Furthermore, the common occurrence of female desertion among shorebirds also supports the idea that males play the predominant role in nest defense (Gibson 1971; Hussell and Page 1976; Ashkenazie and Safriel 1979; Maxson and Oring 1980; Walters 1982; Howe 1982; Komeda 1983).

\section{Natural predators}

Despite variation in predator form and in number of approaches by different species, it was possible to make comparisons between ground (mammalian and avian) and aerial (avian) predators. The more intense defense behavior such as injury-feigning was more often directed towards ground predators. Responses to aerial predators usually involved sitting tight on the nest or quietly departing from the vicinity of the nest. Furthermore, intense responses were given to ground predators regardless of whether they were avian or mammalian even though avian predators tended to ignore injuryfeigning killdeer. The effectiveness with which shorebirds distract potential predators has been noted by many authors (Vogt 1938; Larson 1960; Bengtson 1970; Gibson 1971; Hobbs 1972; Jones 1979). Killdeer successfully distracted potential predators from eggs and chicks, during 1012 of 1017 observed approaches.

The most obvious difference between killdeer responses to human intruders and natural predators was the level of response. This is most likely because of the differences in approach and how close the potential predator was to the nest. The average closest distance that natural predators came to nests or chicks was $21 \mathrm{~m}(n=1017)$. The human intruder always approached to within $1 \mathrm{~m}$ of the nest or chicks, clearly evoking a more intense response.

\section{Conclusions}

The importance of controlling for sex, type of predator, and mode of predator approach has been underestimated when relating temporal patterns of parental defense to theoretical models. The sex of the defending bird is especially important; male killdeer defend more intensely than females. For both sexes defense peaks when offspring are old enough to represent a large investment, but are still able to benefit from continued investment by the parent.

Many factors potentially influence whether the benefits to an individual of continued parental investment outweigh the costs. These include the genetic relatedness of the offspring to a parent, the alternatives available, such as additional mating opportunities, future breeding or other offspring, and the ability of the offspring to gain from continued care. I suggest that patterns of parental defense by killdeer provide further support for the idea that an individual's decision to continue investing in an offspring does not depend upon how much has already been invested, rather, the level of defense correlates most strongly with the vulnerability of the offspring to predation.

Acknowledgements. Financial support for this study was provided by the University of Michigan, a Rackham Predoctoral Fellowship, Rackham Dissertation Grant, and Sigma Xi Grants-in-aid of Research. The Houghton Lake Waste-Water Treatment Authority and Roscommon County, Michigan, gave permission to work on their land; I thank them for cooperating with my research. The Department of Natural Resources of the State of Michigan provided lodging at Houghton Lake and some equipment. Assistance with data analysis by G. Fowler is gratefully acknowledged. For reviews of various drafts of this work I thank R. Alexander, S. Beissinger, E. Curio, G. Fowler, B. Low, D. Rabe, B. Stutchbury, and P. Weatherhead.

\section{References}

Andersson M, Wiklund CG, Rundgren H (1980) Parental defense of offspring: a model and an example. Anim Behav 28:536-542

Armstrong EA (1956) Distraction display and the human predator. Ibis 98:641-654

Ashkenazie S, Safriel UN (1979) Time-energy budget of the Semipalmated Sandpiper (Calidris pusilla) at Barrow, Alaska. Ecology 60:783-799

Barash DP (1975) Evolutionary aspects of parental behavior: distraction display of the alpine accentor. Wilson Bull $87: 367-373$

Bengtson SA (1970) Breeding behaviour of the Purple Sandpiper Calidris maritima in West Spitsbergen. Ornis Scand $1: 17-25$

Bent AC (1929) Life histories of North American shorebirds. Part 2, US Natl Mus Bull 142

Biermann GC, Robertson RJ (1981) An increase in parental 
investment during the breeding season. Anim Behav $29: 487-489$

Brown RG (1962) The aggressive and distraction display behavior of the Western Sandpiper Ereunetes mauri. Ibis 104:1-12

Brunton DH (1986) Fatal antipredator behavior by Killdeer. Wilson Bull 98(4): 605-607

Brunton DH (1987) Reproductive effort of male and female Killdeer (Charadrius vociferus). $\mathrm{PhD}$ dissertation University Michigan, Ann Arbor, Michigan

Brunton DH (1988a) Sexual differences in time budgets of Killdeer during the breeding season. Anim Behav 36:705717

Brunton DH (1988b) Energy expenditure in reproductive effort: the reproductive strategies of male and female Killdeer (Charadrius vociferus). Auk 105:553-564

Buitron D (1983) Variability in the responses of Black-billed Magpies to natural predators. Behaviour 78:209-236

Burger J (1981) Sexual differences in parental activities of breeding Black Skimmers. Am Nat 117:975-984

Curio E (1975) The functional organization of antipredator behaviour in the Pied Flycatcher: a study of avian visual perception. Anim Behav 23:1-115

Curio E, Regelmann K, Zimmerman U (1984) The defence of first and second broods by Great Tit (Parus major) parents: a test of predictive sociobiology. Z Tierpsychol 66:101-127

East M (1981) Alarm calling and parental investment in the Robin, Erithacus rubecula. Ibis 123(2):223-230

Erpino MJ (1968) Nest-related activities of Black-billed Magpies. Condor 70:154-165

Gibson F (1971) The breeding biology of the American Avocet Recurvirostra americana in central Oregon. Condor $73: 444-454$

Gochfeld M (1984) Antipredator behavior: aggressive and distraction displays of shorebirds. In: Burger J, Olla BL (eds) Shorebirds: breeding behavior and populations. Plenum Publ. Corp., New York, pp 289-377

Gottfried BM (1979) Anti-predator aggression in birds nesting in old field habitats: an experimental analysis. Condor $81: 251-257$

Gramza A (1967) Responses of brooding Nighthawks to a disturbance stimulus. Auk 84:72-86

Greig-Smith PW (1980) Parental investment in nest defense by Stonechats (Saxicola torquata). Anim Behav 28:604-619

Harvey PH, Greenwood PJ (1978) Antipredator defence by Stonechats (Saxicola torquata). Anim Behav 28:604-619

Hobbs JN (1972) Breeding of Red-capped Dotterel at Fletcher's Lake Dareton, NSW. Emu 72:121-125

Howe MA (1982) Social organization in a nesting population of eastern Willets (Catoptrophorus semipalmatus). Condor $84: 88-102$

Hussell D, Page GW (1976) Observations on the breeding biology of the Black-bellied Plovers on Devon Island, N.W.T., Canada. Wilson Bull 88:632-653

Jones A (1979) Notes on the behaviour of the Variable Oystercatcher. Notornis 26:47-52

Jourdain FC (1936) The so-called injury feigning in birds. Oologists Rec 16:25-37

Komeda S (1983) Nest attendance of parent birds in the Painted Snipe. Auk 100:48-55

Kruuk H (1964) Predators and anti-predator behavior of the Black-headed Gull (Larus ridibundus L.). Behav Suppl 11:1-129

Larson S (1960) On the influence of the Arctic fox (Alopex lagopus) on the distribution of Arctic birds. Oikos $11: 277-305$
Lazarus J, Inglis IR (1986) Shared and unshared parental investment, parent-offspring conflict and brood size. Anim Behav 34:1791-1804

Lemmetyinen $R$ (1971) Nest defence behaviour of Common and Arctic Terns and its effects on the success achieved by predators. Ornis Fenn $48: 13-24$

Lenington S (1980) Bi-parental care in Killdeer: an adaptive hypothesis. Wilson Bull 92(1): 8--20

Maclean GL (1973) A review of the biology of the Australian Desert Waders, Stilta and Peltohyas. Emu 73:61-70

Maxson SJ, Oring LW (1980) Breeding season time and energy budgets of the polyandrous Spotted Sandpiper. Behaviour $74: 200-263$

Merritt PG (1984) Observer recognition by the Northern Mockingbird. J Field Ornithol 55:252-253

Montevecchi W, Porter J (1980) Parental care and related behavior before fledging in Northern Gannets (Morus bassanus) with reference to other marine birds. In: Burger J, Olla B, Winn H (eds) Behavior of marine animals. Vol. VI. Marine birds. Plenum Press, New York, pp 323-366

Montgomerie RD, Weatherhead PJ (1988) Risks and rewards of nest defence by parental birds. Q Rev Biol 63:167-187

Mundahl JT (1982) Role specialization in the parental and territorial behavior of the Killdeer. Wilson Bull 94(4):515-530

Myers JP (1978) One deleterious effect of mobbing in the Southern Lapwing (Vanellus chilensis). Auk 95:419

Nol E (1980) Factors affecting the nesting success of the Killdeer (Charadrius vociferus) on Long Point, Ontario. M.S. thesis, University Guelph, Guelph, Ontario

Nol E, Lambert A (1984) Comparison of Killdeer, Charadrius vociferus, breeding in Mainland and peninsula sites in Southern Ontario. Can Field Nat 98:7-11

Patterson TL, Petrinovich L, James DK (1980) Reproductive value and appropriateness of response to predators by White-crowned Sparrows. Behav Ecol Sociobiol 7:227-231

Phillips RE (1972) Sexual and agonistic behavior in the Killdeer (Charadrius vociferus). Anim Behav 20:1-9

Pierotti R (1981) Male and female parental roles in the Western Gull under different environmental conditions. Auk $98: 532-549$

Ratcliffe DA (1977) Observations on the breeding of the Golden Plover in Great Britain. Bird Study 23:63-116

Regelmann K, Curio E (1983) Determinants of brood defence in the Great Tit Parus major L. Behav Ecol Sociobiol 13:131-145

Shields WM (1984) Barn Swallow mobbing: self-defence, collateral kin defence, group defence, or parental care? Anim Behav 32:132-148

Simmons KEL (1955) The nature of the predator reactions of waders towards humans, with special reference to the role of the aggressive-, escape- and brooding-drives. Behaviour $8: 130-173$

Skutch AF (1949) Do tropical birds rear as many young as they can nourish? Ibis $91: 430-455$

Trivers RL (1972) Parental investment and sexual selection. In: Campbell B (ed) Sexual selection and the descent of man, 1871-1971. Aldine Press, Chicago, pp 136-179

Vogt W (1938) Preliminary notes on the behavior and ecology of the eastern Willet. Proc Linn Soc NY 49:8-42

Walters JR (1982) Parental Behavior in Lapwings (Charadriidae) and its relationships with clutch sizes and mating systems. Evolution 36:1030-1040

Weatherhead PJ (1979) Do Savannah Sparrows commit the Concorde Fallacy? Behav Ecol Sociobiol 5:373-381

Weatherhead PJ (1982) Risk-taking by red-winged blackbirds and the Concorde Fallacy. Z Tierpsychol 60:199-208 